\title{
Meta-Analysis of Clinical Outcomes of Tricuspid Valve Replacement
}

\author{
SHERIF NEGM, M.Sc.; AMR A. ARAFAT, M.D.; EL-ATAFY M. EL-ATAFY, M.D. and \\ HOSAM F. FAWZY, M.D.
}

The Department of Cardiothoracic Surgery, Faculty of Medicine, Tanta University, Egypt

\begin{abstract}
Background: The long-term results of Tricuspid Valve Replacement (TVR) depend on factors related to the original valve disease more than on the prosthesis type. Tricuspid valve prosthesis; either mechanical or bioprosthetic, should be chosen according to the individual patient's characteristics.

Aim of Study: The aim of the study was to analyze the clinical results of tricuspid valve replacement, comparing the different types of tricuspid valve prostheses.

Patients and Methods: A meta-analysis study was done to evaluate TVR results in adults in the literature published in the period of 20 years "1995: 2015", focusing on literature published in English comparing mechanical valves to bioprosthetic valves. We performed a search over published literature of different databases "Embase, PubMed, Ovid, Justor, Science Direct, and Wiley Blackwell."

Results: The total of 17 studies evaluating 1020 mechanical valve and 1199 bioprosthetic valve patients were included in the meta-analysis. Valve thromboses, and emboli are less reported with bioprosthetic valve $(\mathrm{RR}=6.52 ; 95 \% \mathrm{CI}: 3.00$ 14. $15 ; p<0.00001)$ and $(\mathrm{RR}=2.25 ; 95 \% \mathrm{CI}: 1.14,4.46 ; p=$ $0.02)$ respectively. There was no statistically significant difference between valve types as regards to bleeding, heart block, low cardiac output, valve failure, infective endocarditis, stroke, and renal failure.

Conclusion: The type of the tricuspid valve prosthesis should be chosen based on patient's characteristics but occasionally it's equivocal, that's when the bioprosthetic valve should be preferred because of its less morbidity.
\end{abstract}

Key Words: Tricuspid valve replacement-Mechanical valves - Bioprosthetic valves.

\section{Introduction}

HISTORICALLY, Tricuspid Valve (TV) surgery has been associated with high operative mortality and morbidity and considered a marker for endstage valvular heart disease [1]. When the anatom-

Correspondence to: Dr. Sherif Mohamed Ahmed Negm, E-Mail: dr.sherifnegm@gmail.com ical abnormality of the TV leaflets is severe, Tricuspid Valve Replacement (TVR) is necessary [3], especially in re-operations on highly deformed valves and in the case of a second or third intervention performed for residual or recurrent Tricuspid Regurgitation (TR) [2] . Currently, right sided valve replacement might be considered for patients with only mild symptoms [2], avoiding the high mortality risk associated with right ventricular dilatation in late intervention [3]. The outcome of TV surgery is less predictable than that of other valves; with higher risk and a worse outcome than the mitral valve replacements, because of the complex anatomy and late repeated interventions [2] The durability of mechanical heart valves leads to low rates of re-operation, compared with that of bio-prosthetic valves. But, mechanical valve dysfunction (nonstructural), such as prosthetic leaflet restriction due to thrombus or pannus formation and para-valvular leak, has been problematic [4] There is insufficient data to determine which valve prosthesis is better for tricuspid valve replacement [ $\boldsymbol{s}$. The objective of this meta-analysis is to compare the outcomes of TVR using mechanical versus bioprosthetic valves in the studies published in 20 years.

\section{Material and Methods}

We identified relevant studies published in the past 20 years (1995 to 2015), through Embase, PubMed, Ovid, Science Direct, Wiley Blackwell and Justin and we included related articles found through manual search. The data were reviewed by the 1 st and 2 nd authors followed by the third one to confirm that the studies meet the inclusion criteria. The text strings used were formatted for PubMed as 1- (Tricuspid valve disease) 2- AND 3- (Tricuspid valve replacement) 4- AND 5- (Mechanical-OR-Bioprosthetic) or ((Mechanical) then (Bioprosthetic)). To further reduce the probability 
of losing any major related study, all references of included studies were evaluated. Data extraction was conducted independently by two authors and a third one if there is a discrepancy in the collected data.

According to the pre-set strict criteria "intrainstitutional comparison between the outcomes of bioprosthetic and mechanical tricuspid valve in adult patients" relevant papers in English were selected from the search result. The exclusion criteria were: Studies that have no direct comparison between the bioprosthetic and the mechanical valve studies that do not report the outcomes and studies that were produced at the same institution and there was a sample overlap, in this case, the most updated study was included.

After excluding non-relevant studies, we found 17 studies comparing the two valves. We found 1724 from search and related articles, after removal of duplicates, 1505 studies remained. From them, 1319 were excluded: 1189 irrelevant studies, 10 of percutaneous TVR, 23 of tricuspid valve repair, 58 before 1995 or after 2015, 26 including children, infants, and neonates, ten not in English, 2 of cadavers, and 1 in cardiac transplantation patients. Then we fully assessed 186 studies to include 17 and exclude 169: 25 of population less than 10 patients, 1 study was repeated with the same institution data, 104 abstract, editorial, conference papers, and not enough supplied data, 9 did not discuss morbidity, 5 studies on mechanical valves only, 9 on bioprosthetic tricuspid valve only, 16 studies on TVR with no data comparison Fig. (1).

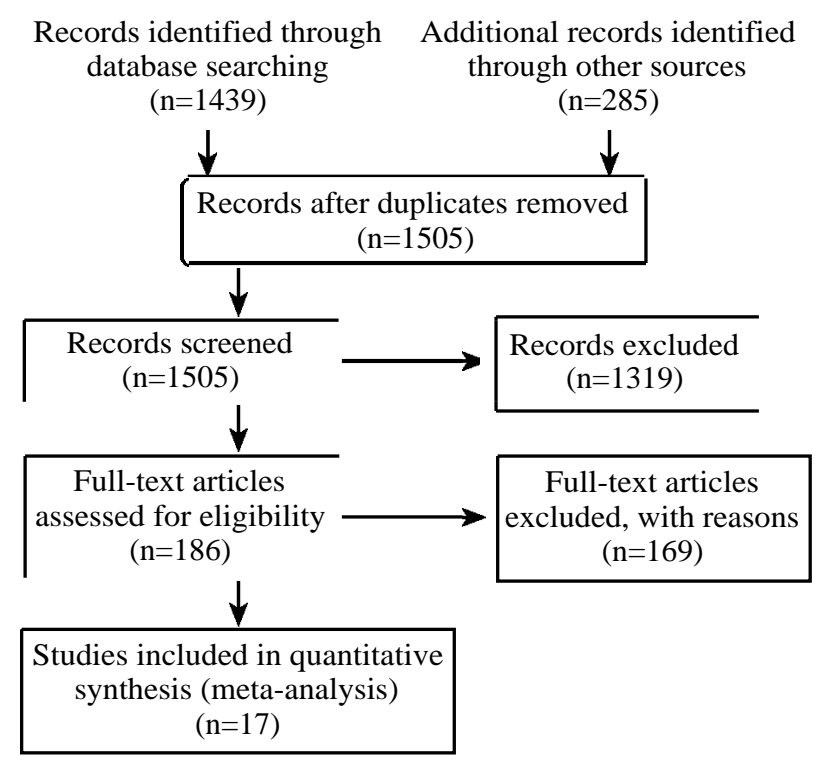

Fig. (1): PRISMA flowchart (preferred reporting items for systematic reviews and meta-analyses).

\section{Statistical analysis:}

Forest plots were used to summarize the results of each outcome. The effect size is shown as a square, and its size is related and proportionate to the weight of each study. Black diamond presents the pooled effect size which indicates the overall results. If it lies completely at one side of the solid central vertical line without crossing it, this indicates significant results [6-20]. Statistical significance was set at a $p$-value of 0.05 or less.

Funnel plots were used to asses publication bias, and the dots around the central vertical line have to be distributed in an equal way on both sides to exclude publication bias [6-20]

The endpoints were postoperative morbidity including; valve thromboses, emboli, heart block, bleeding, low cardiac output, infective endocarditis, valve failure, stroke, and renal failure.

All analyses were performed using RevMan (Version 5.3. Copenhagen: The Nordic Cochrane Centre, the Cochrane Collaboration, 2014).

\section{Results}

\section{Study summary:}

Database research yielded 17 studies meeting the inclusion criteria and reporting an institutional comparison between the tricuspid bioprosthetic valve and the mechanical valve. These studies are presenting the outcome of 1020 mechanical and 1199 bioprosthetic valve. Studies are summarized in (Table 1) which shows the date of publication, number of patients, the time range of the operation and geographical distribution of the studies.

\section{Post-operative thrombosis:}

Fourteen studies compared thrombosis with mechanical Vs. bioprosthetic valve, all of them favored the bioprosthetic valve, and our metaanalysis revealed the significantly lower risk of thrombosis with bioprosthetic valve, and there is no publication bias (Pooled RR $=6.52 ; 95 \% \mathrm{CI}$ : $3.00-14.15$ and $p$-value $>0.001)$ Figs. $(2 \mathrm{~A}, 3)$.

\section{Post-operative valve failure:}

Twelve studies compared valve failure in patients receiving bioprosthetic Vs. mechanical valve, 9 of them favored the mechanical valve and three favored bioprosthetic valve. Our meta-analysis revealed insignificant difference between the both valves with no publication bias (Pooled RR $=0.51 ; 95 \%$ CI: 0.25-1.04 and $p$-value=0.07) Figs. $(2 \mathrm{~B}, 4)$. 


\section{Post-operative embolic events:}

Post-operative embolic events were presented by five studies comparing mechanical and bioprosthetic valve from which 4 favored the bioprosthetic valve and one favored the mechanical valve. Our results showed that bioprosthetic valve has significant better outcome (Pooled RR $=2.25 ; 95 \%$ CI: 1.14-4.46 and $p$-value=0.02) Fig. (5).

Post-operative stroke and cerebrovascular events:

Six studies reported post-operative stroke, and cerebrovascular events, 4 of them favored the mechanical valve and 2 favored the bioprosthetic valve, our meta-analysis revealed insignificant difference for both valves (Pooled RR $=0.63 ; 95 \%$ CI: $0.22-1.80$ and $p$-value=0.39) Fig. (6).

\section{Post-operative infective endocarditis:}

Five studies compared infective endocarditis between both valves (mechanical and bioprosthetic), 2 of them favored the mechanical valve while 3 favored the bioprosthetic valve. Our meta-analysis revealed no significant difference was between the both valves (Pooled $\mathrm{RR}=1.09$; 95\% CI: 0.35-3.39 and $p$-value $=0.89$ ).

\section{Post-operative low cardiac output:}

Five studies compared post-operative low cardiac output in mechanical Vs. bioprosthetic tricus- pid valves, 2 supported the mechanical valve, and 3 supported the bioprosthetic valve. Our metaanalysis revealed insignificant difference between both valves (Pooled RR=0.95; 95\% CI: 0.62-1.45 and $p$-value $=0.82$ ).

\section{Post-operative atrioventricular block:}

Four studies compared post-operative atrioventricular block in mechanical and bioprosthetic tricuspid valves, all of them supported the mechanical valve, but no significant difference was found Pooled RR=0.61 (95\% CI: $0.25-1.50$ and $p$-value $=$ 0.279 ).

\section{Post-operative renal failure:}

Post-operative renal dysfunction was reported in 4 studies 2 of them favored the mechanical valve and 2 favored the bioprosthetic valve, and there was the non-significant difference between both valves (Pooled $\mathrm{RR}=0.73$ (95\% CI: $0.38-1.39$ and $p$-value $=0.42$ ).

\section{Post-operative bleeding:}

Post-operative bleeding was reported by nine studies from which 5 showed better results with the mechanical valve and 4 showed better results with the bioprosthetic valve, and our meta-analysis showed a statistically non-significant difference for the two valves (Pooled RR=0.96; 95\% CI: 0.511.81 and $p=0.91$ ).

Table (1): Summary of the studies included in the meta-analysis.

\begin{tabular}{|c|c|c|c|c|c|c|}
\hline First author & $\begin{array}{c}\text { Publication } \\
\text { date }\end{array}$ & $\begin{array}{l}\text { Patients } \\
\text { number }\end{array}$ & $\begin{array}{l}\text { Patients receiving } \\
\text { a mechanical valve }\end{array}$ & $\begin{array}{l}\text { Patients receiving a } \\
\text { bioprosthetic valve }\end{array}$ & $\begin{array}{l}\text { Time range of } \\
\text { the operation }\end{array}$ & $\begin{array}{c}\text { Location of } \\
\text { the study }\end{array}$ \\
\hline Scully HE et al., [7] & 1995 & 60 & 32 & 28 & 1978:1993 & Canada \\
\hline Van Nooten GJ et al., [8] & 1995 & 146 & 77 & 69 & 1967:1987 & Belgium \\
\hline Hayashi J et al., [9] & 1996 & 29 & 15 & 14 & 1978:1995 & Japan \\
\hline Ratnatunga CP et al., [10] & 1998 & 425 & 200 & 225 & 1986:1997 & UK \\
\hline Mehmet Kaplan et al., [11] & 2002 & 129 & 97 & 32 & 1980:2000 & Turkey \\
\hline Carrier $M$ et al., [12] & 2003 & 97 & 15 & 82 & 1977:2002 & Canada \\
\hline Farzan Filsoufi et al., [13] & 2005 & 81 & 47 & 34 & 1985:1999 & USA \\
\hline Tokunaga $S$ et al., [14] & 2008 & 23 & 4 & 19 & 1975:2004 & Japan \\
\hline Moraca RJ et al., [15] & 2009 & 93 & 21 & 72 & 1986:2006 & USA \\
\hline Toplisky Y et al., [1 6] & 2011 & 189 & 35 & 154 & & \\
\hline Ho Young Hwang et al., [17] & 2012 & 119 & 70 & 49 & 1996:2010 & South Korea \\
\hline Cho WC et al., [18] & 2013 & 104 & 59 & 45 & 1991:2009 & South Korea \\
\hline Chang BC et al., [19] & 2013 & 138 & 103 & 35 & 1978:2003 & South Korea \\
\hline Capitán JR [20] & 2013 & 35 & 24 & 11 & 1996:2010 & Spain \\
\hline Ho Young Hwanget et al., [21] & 2014 & 224 & 121 & 103 & 1994:2012 & South Korea \\
\hline Songur CM et al., [22] & 2014 & 132 & 64 & 68 & $1993: 2011$ & Turkey \\
\hline Connolly HM et al., [23] & 2015 & 195 & 36 & 159 & 1985:2012 & USA \\
\hline
\end{tabular}




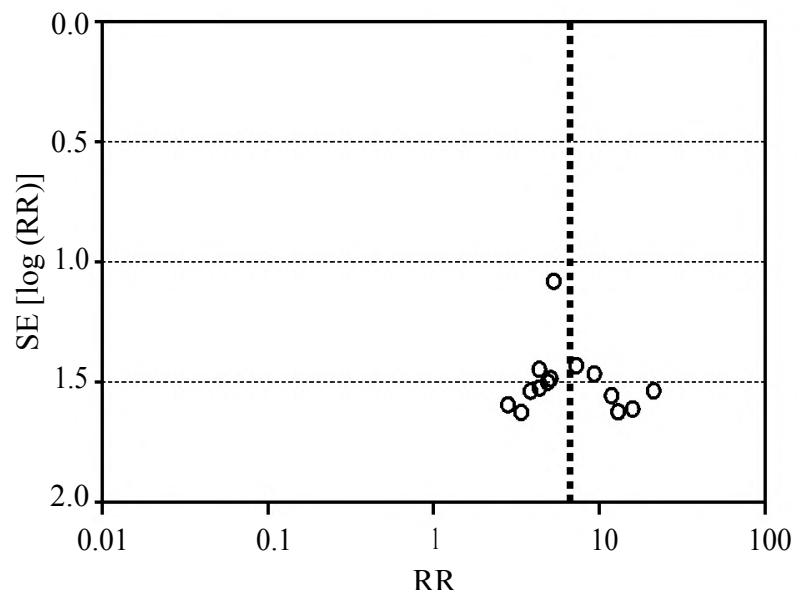

Fig. (2A): Publication bias funnel plots for thrombosis-equal distribution around vertical central line $=$ no publication bias.

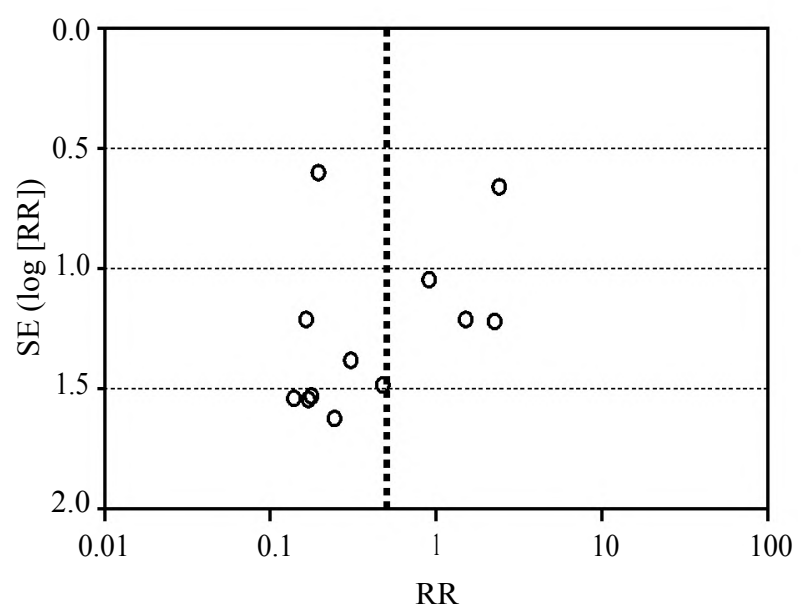

Fig. (2B): Publication bias funnel plots for valve failure-equal distribution around vertical central line $=$ no publication bias.

Study name Songur CM et al. 2014

Ho Young Hwanget et al. 2014

Cho WC et al. 2013

Chang BC et al. 2013

Jorge Rodr?guez-Capit?n et al. 2013

Ho Young Hwang et al. 2012

Topilsky $Y$ et al. 2011

Tokunaga $S$ et al. 2008

Farzan Filsoufi et al. 2005

Carrier M et al. 2003

Ratnatunga CP et al. 1998

Hayashi $\mathrm{J}$ et al 1996

Scully HE et al 1995

\section{Risk ratio and $95 \% \mathrm{Cl}$}

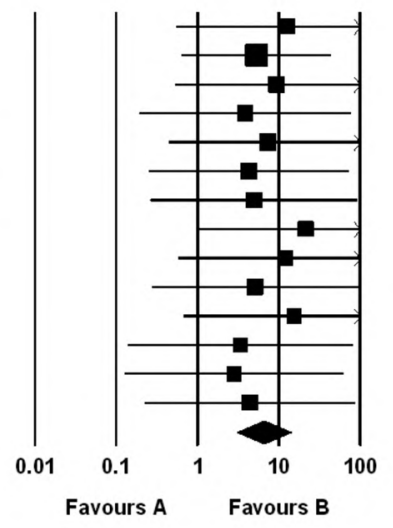

Fig. (3): Forest plot of post-operative thrombosis, in favor of bioprosthetic valve-CI: Confidence Interval, (A) Mechanical valve, (B) Bioprosthetic valve-(Pooled $\mathrm{RR}=6.52 ; 95 \% \mathrm{CI}: 3.00-14.15$ and $p$-value $>0.001$ ).

\author{
Study name
}

Risk ratio and $95 \% \mathrm{Cl}$

Ho Young Hwanget et al. 2014 Chang BC et al. 2013

Cho WC et al. 2013

Ho Young Hwang et al. 2012

Topilsky $Y$ et al. 2011

Tokunaga $S$ et al. 2008

Farzan Filsoufi et al. 2005

Carrier M et al. 2003

Mehmet Kaplan et al. 2002

Ratnatunga CP et al. 1998

Scully HE et al 1995

Van Nooten GJ et al. 1995

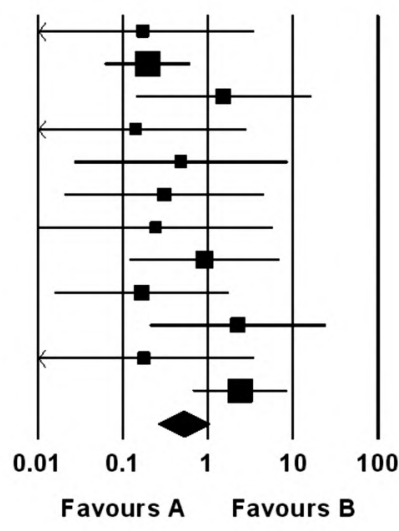

Fig. (4): Forest plot of post-operative valve failure-CI; Confidence Interval, (A) Mechanical valve, (B) Bioprosthetic valve-(Pooled $\mathrm{RR}=0.51 ; 95 \% \mathrm{CI}: 0.25-1.04$ and $p$-value $=0.07$ ).

\section{Study name}

Risk ratio and $95 \% \mathrm{Cl}$

Songur CM et al. 2014

Cho WC et al. 2013

Jorge Rodr?guez-Capit?n et al. 2013

Chang BC et al. 2013

Scully HE et al 1995

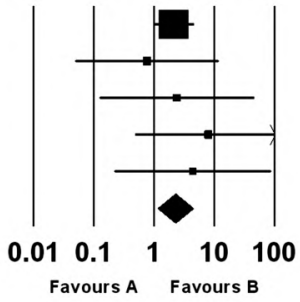

Fig. (5): Forest plot of post-operative embolic events- in favor of the bioprosthetic valve, CI; Confidence Interval, (A) Mechanical valve, (B) Bioprosthetic valve(Pooled $\mathrm{RR}=2.25 ; 95 \% \mathrm{CI}: 1.14-4.46$ and $p$ value $=0.02$ ).

Study name

Risk ratio and $95 \% \mathrm{Cl}$

Ho Young Hwanget et al. 2014 Chang BC et al. 2013 Jorge Rodr?guez-Capit?n et al. 2013 Ho Young Hwang et al. 2012

Farzan Filsoufi et al. 2005 Scully HE et al 1995

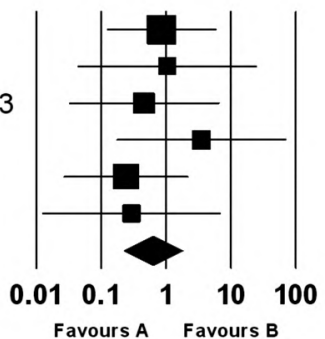

Fig. (6): Forest plot of post-operative stroke and cerebrovascular events-CI; Confidence Interval, (A) Mechanical valve, (B) Bioprosthetic valve-(Pooled $\mathrm{RR}=0.63$; $95 \%$ CI: $0.22-1.80$ and $p$-value $=0.39$ ). 


\section{Discussion}

Tricuspid valve repair is the first option in tricuspid valve surgery [24]. When repair is not feasible, and tricuspid valve replacement becomes mandatory, the question which prosthesis is better in this tricuspid position is still debatable. No optimum valve substitute is available and comparing tricuspid bioprosthesis and mechanical valves; each one has its advantages and disadvantages. Recent guidelines in the management of the valvular heart disease stated that not enough evidence of the superiority of one valve over the other [25]

Bioprosthetic valves were considered the best choice for tricuspid valve replacement as anticoagulation is not needed, and degeneration is expected on a more extended period than the mitral valves due to the low right side pressure. However, some studies reported short durability of the bioprosthetic valves and determination occurred in less than nine years [12-26], and some were associated with pannus formation [27,28]. While studies proved the new bi-leaflets mechanical valves function in low gradient with optimum durability [11]

We did a meta-analysis study to compare the outcome and post-operative morbidity following mechanical and bioprosthetic tricuspid valves. These data were presented by studies comparing the two group of patients under the same postoperative care and in the same institution.

For post-operative valve thrombosis, in general, the tricuspid valve is bigger than a mitral, and aortic valve with low velocity across it increases the risk of thrombosis. All the 14 studies showed better outcome with the bioprosthetic valve, which justifies the rationale of most of the surgeons preferring bioprosthetic valve, and that is explained by the high risk of thrombosis with mechanical valve when the INR is below therapeutic level [22,23] and reported with multiple redo cases [22] and some of them required re-replacement [21] The same for post-operative embolic events, the majority of the studies (4 of 5) favored the bioprosthetic valve, which could be explained by the high risk of thrombosis with the mechanical valve [22,23] even with anticoagulation treatment [18]. Several factors could affect the incidence of embolic events, such as ventricular function, valve position, rhythm, prosthetic valve type, coagulation status, and patient compliance [19]. But infective endocarditis either early or late was nearly the same in both groups, even though thrombosis is significantly more with the mechanical valve $[\mathbf{8 , 2 2 , 2 3 ]}$. Infective endocarditis increased the incidence of reoperation [8-14] and increased mortality [7-11].

On the other side, the majority of the studies ( 9 of 12) showed better postoperative valve failures results with the mechanical valve, and that's related to its longer durability as compared to the bioprosthetic valve [13-19]. Mechanical valve failure was due to pannus formation, and the paravalvular leak which was reported more frequently with the mechanical valves $[\mathbf{1 9 , 2 9 ]}$. These complications make the bioprosthetic valve the valve of choice if no other indications necessitate the insertion of mechanical valve like concomitant anticoagulation therapy.

Post-operative stroke and cerebrovascular presented as cerebral infarction [13-19], stroke $[2,7,13,19,21]$ and mostly related to short periods of perioperative hypoperfusion or patients' related risk factor which could occur with both valve types [19]. Other complications including atrioventricular block, renal failure, low cardiac output, and bleeding occurred equally in both valve types with no significant difference. Causes of death following TVR were a progressive myocardial failure and acute pulmonary edema $[\mathbf{7 , 1 3 , 2 1 ]}$, bleeding and reoperation $[2,7,13,21]$ and renal failure requiring dialysis [13,21]

\section{Study strength and limitations:}

The study contributes to the clinician knowledge to which TV prosthesis to choose for their patients based on literature evidence during 20 years. All the included studies are retrospective which presents a study limitation; however, no available randomized trial comparing valve types in the literature due to the infrequency of the procedure.

\section{Conclusion:}

The choice of the prosthesis in tricuspid valve replacement depends on the risk factors of the patient as each type of prosthesis has its own risk and complications. Re-operation, bleeding, valve failure, infective endocarditis, cerebrovascular events, low cardiac output, AV block, and renal failure didn't differ significantly between the two types. Bioprosthetic valve is a significantly lower risk of thrombosis and embolism. So, when the choice of the prosthesis is equivocal, the bioprosthetic valve should be preferred because of its less morbidity.

\section{References}

1- JEGANATHAN R., ARMSTRONG S., AL-ALAO B. and DAVID T.: The Risk and Outcomes of Reoperative Tricuspid Valve Surgery, The Annals of Thoracic Surgery, January, Volume 95, Issue 1, Pages 119-24, 2013. 
2- JORGE RODRÍGUEZ-CAPITÁN, JUAN J. GÓMEZDOBLAS, LETICIA FERNÁNDEZ-LÓPEZ, RAÚL LÓPEZ-SALGUERO, MANUEL RUIZ, INÉS LERUITE, FERNANDO CABRERA-BUENO, MARÍA J. MATARÓ-LÓPEZ, GEMMA SÁNCHEZ-ESPÍN, JOSÉ M. MELERO-TEJEDOR, CARLOS PORRAS-MARTÍN, MIGUEL SUCH and EDUARDO De TERESA: Shortand Long-term Outcomes of Surgery for Severe Tricuspid Regurgitation, Revista Española de Cardiología (English Edition), August, Volume 66, Issue 8, Pages 629-35, 2013.

3- RICCI D., BOFFINI M., BARBERO C., EL-QARRA S., MARCHETTO G. and RINALDI M.: Minimally invasive tricuspid valve surgery in patients at high risk. Journal of Thoracic and Cardiovascular Surgery, 147: 3-996-1001, 2014.

4- YOSHIO MISAWA and KATSUO FUSE: Left Ventricular Remodeling After Valve Replacement in Patients with Isolated Aortic Regurgitation, Circulation, 107: e208e209, 2003

5- TOKUNAGA S., MASUDA M., SHIOSE A., TOMITA Y., MORITA S. and TOMINAGA R.: Long-term results of isolated tricuspid valve replacement. Asian Cardiovasc. Thorac. Ann., 16: 25-8, 2008.

6- KEVIN PHAN, DAVID H. TIAN, CHRISTOPHER CAO, DEBORAH BLACK and TRISTAN D. YAN: Systematic review and meta-analysis: Techniques and a guide for the academic surgeon, Ann. Cardiothoracic. Surg., 4 (2): 112$22,2015$.

7- SCULLY H.E. and ARMSTRONG C.S.: Tricuspid valve replacement: Fifteen years of experience with mechanical prostheses and bio prostheses. J. Thorac. Cardiovasc. Surg., 109: 1035-41, 1995.

8- VAN NOOTEN G.J., CAES F., TAEYMANS Y., VAN BELLEGHEM Y., FRANÇOIS K., De BACQUER D. DEUVAERT F.E., WELLENS F. and PRIMO G.: The valve choice in tricuspid valve replacement: 25 years of experience. Eur. J. Cardiothorac. Surg., 9: 441-7, 1995.

9- HAYASHI J., SAITO A., YAMAMOTO K., WATANABE H., OHZEKI H. and EGUCHI S.: Is a bioprosthesis preferable in tricuspidvalve replacement? Thorac. Cardiovasc. Surg., 44: 23 0-3, 1996.

10- RATNATUNGA C.P., EDWARDS M.B., DORE C.J. and TAYLOR K.M.: Tricuspid valve replacement: UK heart valve registry mid-term results comparing mechanical and biological prostheses. Ann. Thorac. Surg., 66: 19407, 1998.

1 1- MEHMET KAPLAN, M.D., MUSTAFA SINAN KUT, M.D., MAHMUT MURAT DEMIRTAS, M.D., SERDAR CIMEN, M.D. and AZMI OZLER, M.D.: Prosthetic replacement of tricuspid valve: Bioprosthetic or mechanical, The Annals of Thoracic Surgery, 73 (2): February, 46773, 2002.

12- CARRIER M., HÉBERT Y., PELLERIN M., BOUCHARD D., PERRAULT L.P., CARTIER R., BASMAJIAN A., PAGÉ P. and POIRIER N.C.: Tricuspid valve replacement: An analysis of 25 years of experience at a single center. Ann. Thorac. Surg., 75: 47-50, 2003.

13- FARZAN FILSOUFI, M.D., ANI C. ANYANWU, M.D., SACHA P. SALZBERG, M.D., TIM FRANKEL, M.D., LAWRENCE H. COHN, M.D. and DAVID H. ADAMS, M.D.: Long-Term Outcomes of Tricuspid Valve Replace- ment in the Current Era, The Annals of Thoracic Surgery, 80 (3), September, 845-50, 2005

14- TOKUNAGA S., MASUDA M., SHIOSE A., TOMITA Y., MORITA S. and TOMINAGA R.: Long-term results of isolated tricuspid valve replacement. Asian Cardiovasc. Thorac. Ann., 16: 25-8, 2008.

15- MORACA R.J., MOON M.R., LAWTON J.S., GUTHRIE T.J., AUBUCHON K.A., MOAZAMI N., PASQUE M.K. and DAMIANO R.J. Jr.: Outcomes of tricuspid valve repair and replacement: A propensity analysis. Ann. Thorac. Surg., Jan., 87 (1): 83-8; discussion 88-9, 2009.

16- TOPILSKY Y., KHANNA A.D., OH J.K., NISHIMURA R.A., ENRIQUEZ-SARANO M., JEON Y.B., SUNDT T.M., SCHAFF H.V. and PARK S.J.: Pre-operative factors associated with adverse outcome after tricuspid valve replacement. Circulation, 123: 1929-39, 2011.

17- HO YOUNG HWANG, M.D., Ph.D., KYUNG-HWAN KIM, M.D., Ph.D., KI-BONG KIM, M.D., Ph.D. and HYUK AHN, M.D., Ph.D.: Mechanical Tricuspid Valve Replacement Is Not Superior in Patients Younger Than 65 Years Who Need Long-Term Anticoagulation, The Annals of Thoracic Surgery, 93 (4): April, 1154-60, 2012.

18- CHANG B.C., LIM S.H., YI G., HONG Y.S., LEE S., YOO K.J., KANG M.S. and CHO B.K.: Long-termclinical results of tricuspid valve replacement. Ann. Thorac. Surg., 81: 1317-24, 2006.

19- CHO W.C., PARK C.B., KIM J.B., JUNG S.H., CHUNG C.H., CHOO S.J. and LEE J.W.: Mechanical valve replacement and bioprosthetic valve replacement in the tricuspid valve position. J. Card. Surg., May, 28 (3): 2127, 2013.

20- MOHER D. 1 ., LIBERATI A., TETZLAFF J. and ALTMAN D.G.: Preferred reporting items for systematic reviews and meta-analyses: The PRISMA statement, PLoS Med., Jul. 21, 6 (7), 2009.

21- HO YOUNG HWANG, M.D., Ph.D., KYUNG-HWAN KIM, M.D., Ph.D., KI-BONG KIM, M.D., Ph.D. and HYUK AHN, M.D., Ph.: Propensity Score Matching Analysis of Mechanical and Bioprosthetic Tricuspid Valve Replacements, The Annals of Thoracic Surgery, 97 (4): April, 1294-99, 2014.

22- SONGUR C.M., SIMSEK E., OZEN A., KOCABEYOGLU S. and DONMEZ T.A.: Long term results comparing mechanical and biological prostheses in the tricuspid valve position: Which valve types are better-mechanical or biological prostheses? Heart Lung Circ., Dec. 23 (12): $1175-8,2014$

23- CONNOLLY H.M., SCHAFF H.V., ABEL M.D., RUBIN J., ASKEW J.W., LI Z., INDA J.J., LUIS S.A., NISHIMURA R.A. and PELLIKKA P.A.: Early and Late Outcomes of Surgical Treatment in, Carcinoid Heart Disease. J. Am. Coll. Cardiol., Nov. 17, 66 (20): 2189-96, 2015.

24- CHOI J.W., JANG M.J., KIM K.H. and HWANG H.Y.: Repair and replacement for the surgical correction of tricuspid regurgitation: A meta-analysis. Eur. J. Cardiothorac. Surg., Apr. 1, 53 (4): 748-55, 2018.

25- NISHIMURA R.A., CARABELLO B.A., FAXON D.P., et al.: Focused update incorporated into the ACC/AHA 2006 guidelines for the management of patients with valvular heart disease: A report of the American College 
of Cardiology/American Heart Association Task Force on Practice Guidelines (Writing Committee to revise the 1998 guidelines for the management of patients with valvular heart disease). Endorsed by the Society of Cardiovascular Anesthesiologists, Society for Cardiovascular Angiography and Interventions, and Society of Thoracic Surgeons. J. Am. Coll Cardiol., 52: e1-142, 2008.

26- RIZZOLI G., De PERINI L., BOTTIO T., MINUTOLO G., THIENE G. and CASAROTTO D.: Prosthetic replacement of the tricuspid valve: Biological or mechanical. Ann. Thorac. Surg., 66: S62-67, 1998.

27- NAKANO K., EISHI K., KOSAKAI Y., et al.: Ten-year experience with the Carpentier-Edwards pericardial xenograft in the tricuspid position. J. Thorac. Cardiovasc. Surg., 111: 605-12, 1996.

28- GUERRA F., BORTOLOTTI U., THIENE G., et al.: Long-term performance of the Hancock porcine bioprosthesis in the tricuspid position. A review of forty-five patients with fourteen-year follow-up. J. Thorac. Cardiovasc. Surg., 99: 838-45, 1990.

29- YOSHIO MISAWA and KATSUO FUSE: Left Ventricular Remodeling After Valve Replacement in Patients with Isolated Aortic Regurgitation, Circulation, 107: e208e209, 2003.

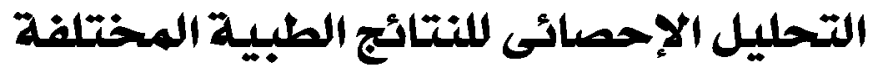

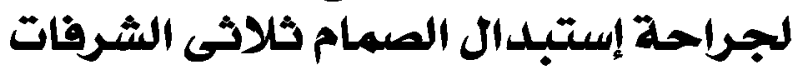

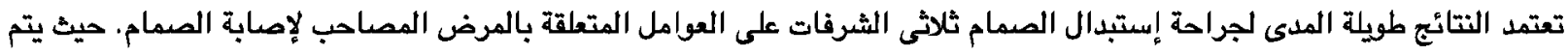

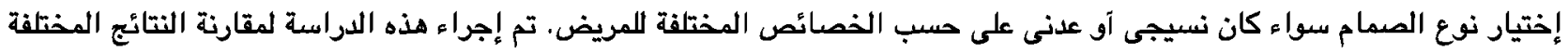 \\ لجراحة إستبدال الصمام ثلاثى الشرفات مع كل نوع من الصمامعات.

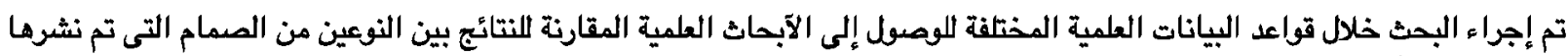

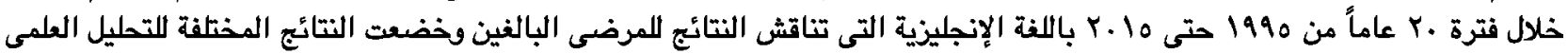

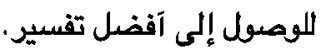

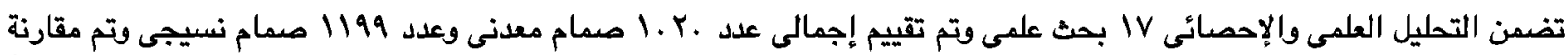

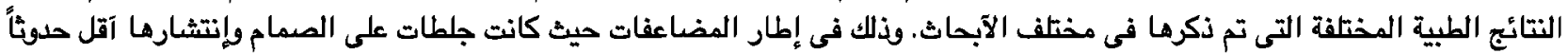

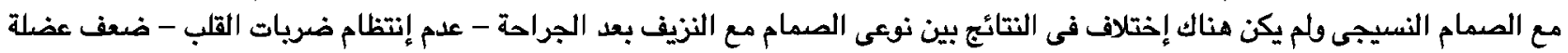

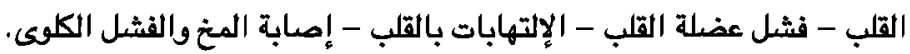

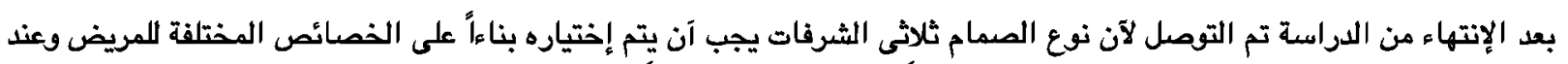

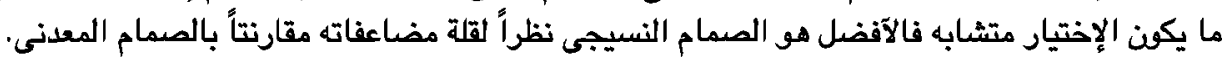

